\section{P103 PROVISION OF PLEURAL DISEASE CARE IN THE PANDEMIC ERA: A SINGLE CENTRE EXPERIENCE}

K Ur Rehman, J Liang, P Sivakumar. Guys and St Thomas' NHS Foundation Trust, London $U K$

\subsection{6/thorax-2021-BTSabstracts.212}

Introduction and Objectives The emergence of COVID-19 disease has had a substantial impact on healthcare services worldwide. We aimed to study its impact on our outpatient pleural service.

Methods We conducted a retrospective review of all new patients who underwent day case procedures by the pleural team from March 2019 to March 2021 and divided them into two groups, pre pandemic group (22 March 2019 to 21 March 2020) \& pandemic group (22 March 2020 to 21 March 2021).

Data was collected on demographics and treatment outcomes.

Results 82 patients were identified in pre pandemic group undergoing 157 procedures in 152 procedural episodes, whereas in pandemic group 83 patients underwent 132 procedures in 122 procedural episodes. Results are summarised in table 1 .

Conclusion Despite the pressures of the pandemic on health care system, pleural activity remained relatively stable. Number of procedural episodes were lower in the pandemic group due to combining the procedures where appropriate and streamlining IPC reviews and drainages by finding alternative ways of managing these patients in the community.

\begin{tabular}{|c|c|c|c|}
\hline & $\begin{array}{l}\text { Pre } \\
\text { pandemic } \\
\text { group }\end{array}$ & $\begin{array}{l}\text { Pandemic } \\
\text { group }\end{array}$ & $p$ value \\
\hline Number of patients & 82 & 83 & \\
\hline Number of procedures & 157 & 132 & \\
\hline Number of procedural episodes & 152 & 122 & \\
\hline Sex - Female (\%) & $35(42.7)$ & $40(48.2)$ & 0.477 \\
\hline Age, mean (SD), yrs & $65.3(14.4)$ & $66.5(14.9)$ & 0.60 \\
\hline $\begin{array}{l}\text { Interval between referral and date of procedure, } \\
\text { median (IQR), days }\end{array}$ & $4(6) n=75$ & $3(6) n=75$ & 0.134 \\
\hline $\begin{array}{l}\text { Interval between sampling \& histocytological } \\
\text { diagnosis, median (IQR), days } \\
\text { Types of procedures (\%) }\end{array}$ & $5(3) n=66$ & $4(4) n=76$ & 0.003 \\
\hline Diagnostic and/or therapeutic pleural aspirate & $60 / 157(38.2)$ & $63 / 132(47.7)$ & \\
\hline Indwelling pleural catheter review \& or drainage & $62 / 157(39.5)$ & 15/132 (11.4) & \\
\hline Indwelling pleural catheter insertion & 20/157 (12.7) & $28 / 132(21.2)$ & \\
\hline Percutaneous pleural biopsy & $7 / 157(4.4)$ & $7 / 132(5.3)$ & \\
\hline Medical thoracoscopy & $3 / 157(1.9)$ & $4 / 132(3)$ & \\
\hline Other procedure & $5 / 157(3.2)$ & 15/132 (11.4) & \\
\hline \multicolumn{4}{|l|}{ Diagnoses\% } \\
\hline Malignancy & $46 / 82(56.1)$ & $45 / 83(54.2)$ & \\
\hline Benign disease & $36 / 82(43.9)$ & $35 / 83(42.2)$ & \\
\hline Infection & $0 / 82(0)$ & $3 / 83(3.6)$ & \\
\hline
\end{tabular}

\section{P104 COVID-19 MORTALITY IN CANCER PATIENTS ON SYSTEMIC ANTI-CANCER TREATMENTS DURING THE SECOND UK SARS-COV-2 WAVE}

S Waring, G Gamtiksulashvili, S Kumar, A D'Souza, S Jiwani, O Taylor, G Collins, Y Narayan, K Patrick, A Sethuraman, S Naik, S Kuckreja, R Ragatha, M Anwar, U Ekeowa, P Russell. The Princess Alexandra Hospital, Harlow, Essex, UK

\subsection{6/thorax-2021-BTSabstracts.213}

Background Recent multicentre registries have shown cancer patients infected with SARS-CoV-2 have significantly higher mortality compared to patients without cancer ${ }^{1}$. Cancer-specific features associated with worse outcomes include advanced tumour stage, disease progression and lung cancer. ${ }^{1}$ Systemic anti-cancer treatments (SACT - chemotherapy, immunotherapy, targeted and hormone therapy) have been postulated to increase mortality from COVID-19 in cancer patients. Here, we aim to determine if cancer patients on SACT have a higher risk of mortality than those not on active treatment.

Methods We retrospectively analysed cancer patients admitted to a Greater London District General Hospital between 1st November 2020 and 28th February 2021 with RT-PCR positive COVID-19. SACT was considered present if administered within 3 months of admission. Mortality encompassed hospitalised patients and those up to 28 days post-discharge. Association of cancer-specific demographics and mortality was assessed using logistic regression analyses adjusting for age, sex and comorbidities.

Abstract P104 Table 1 Mortality rate after presentation of COVID-19 by: tumour type, time from cancer diagnosis, cancer stage, progression of disease, and systemic anti-cancer treatment (SACT).

\begin{tabular}{|c|c|c|c|c|c|}
\hline & & Number & $\begin{array}{l}\text { mortality } \\
\text { number }\end{array}$ & $\begin{array}{l}\text { mortality } \\
\%\end{array}$ & $\begin{array}{l}\text { odds } \\
\text { ratio }\end{array}$ \\
\hline \multirow[t]{3}{*}{ Cancer type } & Solid organ & 75 & 28 & 37.3 & 1.32 \\
\hline & Lung & 18 & 11 & 61.1 & $4.66^{* *}$ \\
\hline & Haematological & 29 & 11 & 37.9 & 1.47 \\
\hline \multirow[t]{2}{*}{ Time from diagnosis } & $<12$ months & 55 & 25 & 45.5 & $2.32 * *$ \\
\hline & $>12$ months & 67 & 25 & 37.3 & 1.25 \\
\hline STAGE AT & 4 & 46 & 23 & 50.0 & $2.82^{* * *}$ \\
\hline \multicolumn{6}{|l|}{ DIAGNOSIS } \\
\hline & 3 & 26 & 13 & 50.0 & 2.17 \\
\hline & 2 & 14 & 5 & 35.7 & 1.22 \\
\hline & 1 & 31 & 8 & 25.8 & 0.77 \\
\hline & 0 & 5 & 1 & 20.0 & 0.46 \\
\hline disease progression & Yes & 38 & 22 & 57.9 & $4.60^{* * *}$ \\
\hline \multicolumn{6}{|l|}{ ( $<3$ months BEFORE } \\
\hline \multicolumn{6}{|l|}{ COVID-19) } \\
\hline & No & 84 & 28 & 33.3 & 1.07 \\
\hline SACT & Yes & 53 & 69 & 34.0 & 1.49 \\
\hline \multicolumn{6}{|l|}{ ( $<3$ months BEFORE } \\
\hline \multicolumn{6}{|l|}{ COVID-19) } \\
\hline & No & 69 & 32 & 46.4 & $1.80^{* *}$ \\
\hline
\end{tabular}


Results Mortality rate was significantly higher in 122 cancer patients with COVID-19 than 1220 patients without cancer (OR 1.653, p=0.014), especially in patients with lung cancer (OR 4.664, $\mathrm{p}=0.002$ ). 55 patients diagnosed with cancer within one year had a significantly higher mortality (OR 2.32, $\mathrm{p}=0.004)$. Stage 4 , but not earlier stages of, cancer at diagnosis had much higher mortality (OR 2.82, $\mathrm{p}<0.001)$. Progression of cancer was highly predictive of mortality (OR 4.60, $\mathrm{p}=0.00002$ ). SACT had no significant effect on mortality from COVID-19 disease when compared with cancer patients who had no active treatment. However, cancer patients that did not have SACT within 3 months were more likely to die (OR 1.80, $\mathrm{p}=0.025$ ).

Conclusion Among patients with cancer and COVID-19, mortality was high and associated with cancer-specific features. There was no evidence cancer patients on systemic anti-cancer treatments possessed higher mortality from COVID-19 disease, which correlates with findings from COVID-19 and cancer registries ${ }^{1}$. Patients that did not receive SACT within 3 months before COVID-19 and therefore more likely to have palliative treatment did demonstrate high mortality. Larger studies are needed to confirm the risk of mortality and timing of SACT before COVID-19 disease.

\section{REFERENCE}

1. Lee AJ, et al. British Journal of Cancer 2021;124:1777-1784.

\section{P105 BREAKING BARRIERS TO SINGING FOR LUNG HEALTH DURING THE COVID-19 PANDEMIC}

K Crowley, I Du Rand. Hereford County Hospital, Hereford, UK

\subsection{6/thorax-2021-BTSabstracts. 214}

In 2010 the British Lung Foundation (BLF) launched 'Singing for Lung Health' (SFLH), an initiative to promote singing as part of a group, for patients with chronic lung conditions. This has been shown to be beneficial to mental wellbeing, lung health and quality of life in this group of patients. ${ }^{1}$

In 2019 a local SFLH group was established and around 30 patients with chronic lung conditions participated. When asked, all participants reported an improvement in their physical or emotional health. Personal feedback showed just how positively the sessions had impacted these patients, highlighting the holistic benefits of this initiative in practice (table 1).

The arrival of the COVID-19 pandemic caused the group to be put on hold. This barrier posed a challenge to be overcome and in 2020 the SFLH group was moved online and has continued on this platform ever since.

The majority of the participants reported a decline in their physical health and increase in social isolation as a result of the pandemic. The online SFLH group has provided an outlet for these patients who are among the most isolated and vulnerable groups in the population. As a result of the sessions over $80 \%$ of participants felt an improvement in breath control and 63\% reported an improvement in mood. Personal feedback was extremely complementary showing that the online platform for the sessions has been as effective as it had been in person and that the sessions have been appreciated all the more since the pandemic (table 1).

\begin{tabular}{|c|c|}
\hline In person SFLH Patient feedback & Online SFLH Patient feedback \\
\hline $\begin{array}{l}\text { 'Brilliant, life feels brighter. Breathing } \\
\text { improvement' }\end{array}$ & $\begin{array}{l}\text { 'I feel that my lung capacity has improved a } \\
\text { good deal and that this... has resulted in my } \\
\text { being a good deal less breathless when out } \\
\text { walking.' }\end{array}$ \\
\hline 'uplifted and relaxed' & $\begin{array}{l}\text { 'Breathing and relaxing exercises are very } \\
\text { beneficial to us... also a good social } \\
\text { experience, especially in these very restricted } \\
\text { times' }\end{array}$ \\
\hline $\begin{array}{l}\text { 'positive in what I achieved' } \\
\text { 'meeting people with the same complaint } \\
\text { I have' }\end{array}$ & $\begin{array}{l}\text { 'The class is an utter joy and a lifeline' } \\
\text { 'I can keep fitter than I would otherwise' }\end{array}$ \\
\hline 'improves my outlook on life' & $\begin{array}{l}\text { 'The on-line weekly meeting has been a } \\
\text { major blessing during lockdown' }\end{array}$ \\
\hline 'as long as it takes place I will be there' & 'I enjoy the classes very much' \\
\hline 'keeps me in trim for the next 48 hours' & 'Feel better afterwards' \\
\hline 'Feel better than I did when I arrived' & 'so joyful and uplifting!' \\
\hline $\begin{array}{l}\text { All participants reported an improvement } \\
\text { in their physical or emotional health and } \\
\text { would recommend the SFLH sessions to a } \\
\text { friend with breathing difficulties }\end{array}$ & $\begin{array}{l}80 \% \text { of participants felt an improvement in } \\
\text { breath control and } \\
63 \% \text { reported an improvement in mood. }\end{array}$ \\
\hline
\end{tabular}

This kind of initiative is needed for those struggling with chronic lung conditions and the ability to provide this service online means more patients can benefit.

Special thanks to Annie Summers the group's BLF trained SLFH instructor and to Andi Licqurish and Dennis Schiavon from Encore Enterprises.

\section{REFERENCE}

1. Lord V, Cave P, Hume V, Flude E, Evans A, Kelly J, Polkey M, Hopkinson N. Singing teaching as a therapy for chronic respiratory disease - a randomised controlled trial and qualitative evaluation. BMC Pulmonary Medicine, 2010;10(1).

\section{P106 THE IMPACT OF TECHNICIAN-LED VIRTUAL SPIROMETRY SESSIONS ON THE AVAILABILITY AND QUALITY OF HOME SPIROMETRY RESULTS IN A VIRTUAL CYSTIC FIBROSIS CLINIC}

C Long, T Modzelewski, NJ Bell. Bristol Adult Cystic Fibrosis Centre, Bristol Royal Infirmary, Bristol, UK

\subsection{6/thorax-2021-BTSabstracts.215}

Introduction Spirometry is an essential component of monitoring the health of people with Cystic Fibrosis (CF). Since the Covid-19 pandemic, most consultations have been conducted via video conferencing. All appropriate patients were given MIR Spirobank ${ }^{\circledR}$ portable spirometers (MIR Medical International Research Srl) and asked to send in readings before each clinic. We noticed a fall in the number and quality of spirometry reports available to clinicians in virtual clinics compared to face-to-face reviews. We set out to improve this through a Respiratory Physiologist-led virtual spirometry clinic.

Methods Spirobank ${ }^{\circledR}$ spirometry reports (including grading of quality using ATS/ERS criteria ${ }^{1}$ ) provided by patients attending virtual CF clinics in our CF centre in January 2021 were reviewed. Following this review, a virtual spirometry clinic was established (running before the main clinic) in which the patient performs spirometry via the 'Live Video Exam' app on 